\title{
Child Neurology: Genetically determined dystonias with childhood onset
}

Travis Larsh, MD, Neil Friedman, MBChB, and Hubert Fernandez, MD

Neurology ${ }^{\circledR}$ 2020;94:892-895. doi:10.1212/WNL.0000000000009040
Correspondence

Dr. Larsh

larsht@ccf.org

A previously healthy 10-year-old girl of Croatian descent presented to the pediatric neurology clinic with an abnormal gait. She first noted symptoms 1.5 years prior to presentation, which included flexion-inversion posturing of her left foot while playing soccer. She would drag her left foot, leading to excessive falling. Her family noted that she did not seem to have much difficulty ambulating at the beginning of the day and they did not notice any abnormal posturing of the foot when she woke up in the morning. However, by the evening, they noted her left foot, and occasionally her right foot, would develop a flexion-inversion posture. Her symptoms seemed to be worse when she was tired or after activity. She had previously been evaluated by 2 orthopedic surgeons and a pediatric neurologist and was most recently seen in an emergency department for this problem, with no diagnosis being provided. Workup included a normal lumbar spine MRI and X-rays of both legs.

Physical examination was notable for subtle equinovarus posturing of the patient's left foot only but was otherwise unremarkable. There was no family history of dystonia or parkinsonism. She was started on $100 \mathrm{mg} / \mathrm{d}$ of levodopa, with complete resolution of the dystonic posturing, and she was able to return to playing sports without difficulty. A dystonia gene panel was sent and revealed a heterozygous pathogenic variant in the GTP cyclohydrolase 1 gene (GCH1), diagnostic of DYT5a (Segawa disease), a form of autosomal dominant dopa-responsive dystonia (DRD).

\section{Differential diagnosis}

Dramatic and sustained response to low doses of levodopa distinguishes DRD from the other genetic dystonias (including DYT1) and other conditions such as cerebral palsy and hereditary spastic paraplegias. Other DRDs, including DYT-5b and DYT-SPR, tend to present earlier and have a more severe phenotype in comparison to DYT-5a. Early-onset Parkinson disease (PD) (PINK1, PRKN) can also initially present as gait disturbance due to foot dystonia. Development of motor fluctuations and dyskinesias from chronic levodopa therapy would be atypical in DRD, which can be helpful in distinguishing from PD. Improvement with sleep may be seen in early-onset PD, but typically not as dramatic or sustained as in DRD. Genetic testing is widely available to confirm the diagnosis of the most common forms of genetic dystonias.

\section{Discussion}

The term dystonia was first used in 1911 by Hermann Oppenheim in "About a peculiar cramping sickness in children and adolescents (dysbasia lordotica progressive, dystonia musculorum deformans)." Even in this early description, there was speculation of a genetic etiology. ${ }^{1}$ The first dystonia gene was discovered in 1994 (GCH1), and since then numerous dystonia genes have been identified. ${ }^{2}$ There are 14 confirmed genetic forms that have typical childhood onset (table). Recently, classification of genetic dystonia by inheritance pattern or associated features (isolated dystonia [i.e., simple vs combined] with another movement 
Table Genetically determined dystonia (DYT) with typical childhood onset

\begin{tabular}{|c|c|c|c|c|c|}
\hline Symbol & Gene & Gene locus & Inheritance & Phenotype & Comments \\
\hline \multirow[t]{3}{*}{ DYT1 } & TOR1A & $9 q 32-q 34$ & $A D$ & Early-onset generalized dystonia & Most common \\
\hline & & & & & Ashkenazi Jewish \\
\hline & & & & & Good response to GPi DBS \\
\hline DYT5a & GCH1 & $14 q 22.1-22.2$ & $A D$ & Dopa-responsive dystonia & Clinical case \\
\hline DYT5b & $T H$ & $11 \mathrm{p} 15.5$ & $A R$ & Dopa-responsive dystonia & More severe phenotype than DYT5a \\
\hline- & $S P R$ & $2 p 14-p 12$ & $A R$ & Dopa-responsive dystonia & More severe phenotype than DYT5a \\
\hline \multirow[t]{2}{*}{ DYT6 } & THAP1 & $8 p 11.1$ & $A D$ & Adolescent onset mixed phenotype & Later age at onset than DYT1 \\
\hline & & & & & Prominent cranial involvement \\
\hline DYT8 & MR1 & $2 q 35$ & $A D$ & Paroxysmal nonkinesigenic dyskinesia 1 & \\
\hline DYT10 & PRRT2 & $\begin{array}{l}16 \mathrm{p} 11.2- \\
\mathrm{q} 12.1\end{array}$ & $A D$ & Paroxysmal kinesigenic dyskinesia & \\
\hline DYT11 & SGCE & $7 q 21.3$ & $A D$ & Myoclonus-dystonia & Responsive to alcohol \\
\hline DYT12 & ATP1A3 & $19 q 13.2$ & $A D$ & Rapid onset dystonia-parkinsonism & Poor response to levodopa and DBS \\
\hline DYT18 & SLC2A1 & $1 \mathrm{p} 34.2$ & $A D$ & $\begin{array}{l}\text { Paroxysmal exertion-induced dyskinesia } \\
2\end{array}$ & \\
\hline DYT26 & KCTD17 & $22 q 12.3$ & $A D$ & Myoclonus-dystonia & Dystonia more disabling than DYT11 \\
\hline DYT28 & KMT2B & $19 q 13.12$ & $A D$ & Generalized dystonia & $\begin{array}{l}\text { Prominent cranial, cervical, and laryngeal } \\
\text { involvement }\end{array}$ \\
\hline- & $A D C Y 5$ & $3 q 21.1$ & $A D$ & Chorea, dystonia, and myoclonus & Diurnal paroxysms \\
\hline- & GNAO1 & $16 q 13$ & $A D$ & Hyperkinetic movement disorder & Good response to GPi DBS \\
\hline
\end{tabular}

Abbreviations: $\mathrm{AD}$ = autosomal dominant; $\mathrm{AR}$ = autosomal recessive; $\mathrm{DBS}$ = deep brain stimulation; GPi = globus pallidus pars interna.

disorder [i.e., complex]) has been proposed. ${ }^{3}$ What follows is a concise review of known genetically determined dystonias with typical onset in childhood, organized by associated features.

\section{Isolated dystonias}

DYT1 is the most common hereditary dystonia. It is inherited in an autosomal dominant fashion, with reduced penetrance and variable expressivity. It is particularly common among patients of Ashkenazi Jewish descent. Symptoms typically start before 6 years of age as a focal dystonia in an extremity (more often lower extremity), with spread to other extremities and trunk muscles by the early teens. ${ }^{4}$ The face and neck are not typically involved. ${ }^{2}$ Whereas pharmacologic therapies, including levodopa and anticholinergic drugs, may show variability in therapeutic benefit, deep brain stimulation (DBS) of the globus pallidus pars interna $(\mathrm{GPi})$ has more consistently produced favorable outcomes. ${ }^{5}$

DYT6 shares some similarities with DYT1, but tends to have a later age at onset (average age at onset 19 years), and has prominent cranial involvement. ${ }^{2}$ Dysphonia is often a prominent feature. Treatment is similar to DYT1, with the caveat that GPi DBS has marginal effect on speech. ${ }^{6}$

\section{Combined dystonias}

\section{Dystonia with parkinsonism}

DYT5a is a result of a heterozygous mutation in the $\mathrm{GCH1}$ gene. Most individuals with DYT5a present in childhood with gait disturbance due to lower extremity dystonia, often a rigid pes equinovarus deformity of 1 foot, such as the patient in the case presentation. The dystonia spreads to involve other limbs and the trunk muscles by the teenage years and patients may develop parkinsonian features. ${ }^{4}$ In rare cases, parkinsonian features may be the only sign of the condition. ${ }^{2}$ Early in the course, symptoms show a diurnal fluctuation, with symptoms becoming worse over the course of a day and improving with sleep. ${ }^{4}$ Symptoms become static by early adulthood. There is a female predominance, with possibly a higher prevalence in patients of Eastern European descent. DYT5a is exquisitely responsive to levodopa therapy, with a complete, or near complete, response of symptoms at relatively low doses. Despite being a highly treatable medical condition, there is often considerable diagnostic delay of about 13 years. $^{2}$

DYT5b and DYT-SPR are both inherited in an autosomal recessive fashion (SPR gene mutations can be inherited in an autosomal dominant manner as well, although less commonly). As DRDs, they are exquisitely responsive to levodopa. These 
disorders often have a much more severe phenotype resembling homozygous $\mathrm{GCH} 1$ mutations, and may manifest as an infantile movement disorder with developmental delay. ${ }^{7}$

DYT12 is due to a mutation in the ATP1A3 gene, and is inherited in an autosomal dominant pattern with reduced penetrance. It typically presents in teenagers or young adults with rapid-onset dystonia-parkinsonism (RDP). This is characterized by a sudden onset (hours to weeks) of dystonic spasms (usually the upper limbs), orofacial dystonia, and bulbar symptoms, and is sometimes accompanied by parkinsonian features. ${ }^{2}$ It is often triggered by stressful events such as fever, prolonged exercise, or childbirth. Levodopa and DBS are not beneficial. In addition to RDP, mutations in ATP1A3 are also known to cause alternating hemiplegia of childhood and CAPOS syndrome (cerebellar ataxia, areflexia, pes cavus, optic atrophy, and sensorineural hearing loss). ${ }^{8}$

\section{Dystonia with other dyskinetic movements}

Paroxysmal nonkinesigenic dyskinesia (DYT8) is caused by 2 missense mutations in the myofibrillogenesis regulator 1 (MR1) gene. There is a 2:1 female predominance, and average age at onset is 4 years. Symptoms include attacks consisting of a combination of dystonia and chorea. Attacks last from minutes to hours, but may occur a few times daily in severe cases. ${ }^{2}$ Attacks may be precipitated by alcohol, caffeine, stress, hunger, fatigue, and tobacco. The frequency of attacks tends to decrease with age. Management involves avoidance of precipitating factors; clonazepam may also be beneficial.

The inherited form of paroxysmal kinesigenic dyskinesia (PKD, DYT10) is caused by missense and truncating mutations in the PRRT2 gene. ${ }^{2}$ Age at onset is between 5 and 15 years, and boys are more commonly affected. Attacks consist of combinations of dystonia and chorea lasting a few seconds to minutes, during voluntary movements, several times daily. They are precipitated by startle or making a sudden voluntary movement after a period of rest. PKD responds well to carbamazepine, phenytoin, levetiracetam, and phenobarbital. Attacks diminish with age regardless of treatment.

Mutations in the SLC2A1 gene can cause paroxysmal exertion-induced dyskinesias (DYT18). Attacks consisting of dystonia, chorea, and athetosis are triggered by sustained exercise. Attacks typically last 5-30 minutes. Management involves avoidance of prolonged exercise. Ketogenic diet may also be helpful.

KMT2B-related dystonia (DYT28) is characterized by a progressive disease course that evolves from a focal lower limb dystonia into a generalized dystonia with prominent cervical, cranial, and laryngeal involvement. ${ }^{9}$ Mean age at onset is 7 years. Additional features include developmental delay, choreoathetosis, myoclonus, seizures, eye movement abnormalities, psychiatric comorbidities, spasticity, and sensorineural hearing loss. GPi DBS may be beneficial, particularly in younger patients. ${ }^{9}$
$A D C Y 5$-related dyskinesia presents as a childhood-onset hyperkinetic movement disorder featuring a combination of chorea, myoclonus, and dystonia. ${ }^{10}$ Distinguishing features include diurnal paroxysms with nocturnal attacks of chorea and dystonia. ${ }^{10}$ Treatment with clonazepam or clobazam may be helpful. ${ }^{11}$

In addition to an epileptic encephalopathy, mutations in the GNAO1 gene can cause a childhood-onset progressive movement disorder. Described phenotypic features include chorea, athetosis, dystonia, myoclonus, and stereotypies. ${ }^{12}$ GPi DBS appears to be the most effective treatment for GNAO1-related movement disorders. ${ }^{13}$

\section{Dystonia with myoclonus}

DYT11 involves a mutation in the SGCE gene causing myoclonus-dystonia syndrome (MDS). Inheritance may involve maternal imprinting as paternal inheritance results in almost $100 \%$ symptom expression and maternal inheritance only results in $10 \% .{ }^{14}$ Symptoms typically begin in childhood or early adolescence and consist of myoclonus and dystonia that preferentially involves the upper body. Treatment is with valproate and benzodiazepines. DBS has been consistently reported to improve both myoclonus and dystonia in DYT11. There are reports that $\gamma$-hydroxybutyrate may be helpful. ${ }^{14}$ Symptoms are also very responsive to alcohol, which can lead to dependence in adults.

DYT26 is a more recently described cause of MDS that is a result of heterozygous mutations in the KCTD17 gene. Range of onset is $3-10$ years. ${ }^{15}$ Differentiating factors from DYT11 include that the myoclonus associated with DYT26 tends to be less pronounced in the neck and upper extremities, and the dystonia tends to be more disabling. ${ }^{15}$ There is no improvement with alcohol. GPi DBS may be beneficial. ${ }^{15}$

\section{Study funding}

No targeted funding reported.

\section{Disclosure}

T. Larsh and N. Friedman report no disclosures relevant to the manuscript. H. Fernandez has received honoraria from Prime Education, Inc., International Parkinson and Movement Disorders Society, Carling Communications, Medscape (speaker in CME events), AbbVie, Biogen, GE Health Care, Inventiv, Kyowa Hakko Kirin, Lundbeck, Merz Pharmaceuticals, Voyager, Sunovion, and Pfizer Pharmaceuticals (as a consultant); has received grant and research support from AbbVie, Acadia, Teva, Biotie/Acorda Therapeutics, Civitas, Kyowa/Prostrakan, Michael J. Fox Foundation, Movement Disorders Society, NIH/NINDS, Parkinson Study Group, Rhythm, and Synosia; has no owner interest in any pharmaceutical company; has received royalties from Demos Publishing (serving as a book author/editor); The Cleveland Clinic has a contract with Teva for his role as a co-principal investigator in SD-809 tardive dyskinesia global studies; serves as a member of the publication committee for Acorda Pharmaceuticals but does not receive any personal 
compensation for this; and receives a stipend from the International Parkinson and Movement Disorders Society for serving as Medical Editor of the MDS Web Site. Go to Neurology.org/N for full disclosures.

\begin{tabular}{lll}
\multicolumn{2}{l}{ Appendix } & Authors \\
\hline Name & Location & Contribution \\
\hline $\begin{array}{l}\text { Travis Larsh, } \\
\text { MD }\end{array}$ & $\begin{array}{l}\text { Cleveland } \\
\text { Clinic, } \mathrm{OH}\end{array}$ & $\begin{array}{l}\text { Design and conceptualization of } \\
\text { manuscript, drafting and revision of } \\
\text { manuscript }\end{array}$ \\
\hline $\begin{array}{l}\text { Neil } \\
\begin{array}{l}\text { Friedman, } \\
\text { MBChB }\end{array}\end{array}$ & $\begin{array}{l}\text { Cleveland } \\
\text { Clinic, OH }\end{array}$ & Drafting and revision of manuscript \\
\hline $\begin{array}{l}\text { Hubert } \\
\text { Fernandez, } \\
\text { MD }\end{array}$ & $\begin{array}{l}\text { Cleveland } \\
\text { Clinic, OH }\end{array}$ & Drafting and revision of manuscript \\
\hline
\end{tabular}

\section{References}

1. Klein C, Fahn S. Translation of Oppenheim's 1911 paper on dystonia [“About a peculiar cramping sickness in children and adolescents (dysbasia lordotica progressive, dystonia musculorum deformans")]. Mov Disord 2013;28:851-862.
2. Klein C. Genetics in dystonia. Parkinsonism Relat Disord 2014;20(suppl 1): S137-S142.

3. Marras C, Lohmann K, Lang A, Klein C. Fixing the broken system of genetic locus symbols. Neurology 2012;78:1016-1024.

4. Segawa M, Nomura Y. Genetics and pathophysiology of primary dystonia with special emphasis on DYT1 and DYT5. Semin Neurol 2014;34:306-311.

5. Hale AT, Monsour MA, Rolston JD, Naftel RP, Englot DJ. Deep brain stimulation in pediatric dystonia: a systematic review. Neurosurg Rev Epub 2018 Nov 5.

6. Groen JL, Ritz K, Contarino MF, et al. DYT6 dystonia: mutation screening, phenotype, and response to deep brain stimulation. Mov Disord 2010;25:2420-2427.

7. Willemsen MA, Verbeek MM, Kamsteeg EJ, et al. Tyrosine hydroxylase deficiency: a treatable disorder of brain catecholamine biosynthesis. Brain 2010;133:1810-1822.

8. Sweney MT, Newcomb TM, Swoboda KJ. The expanding spectrum of neurological phenotypes in children with ATP1A3 mutations, alternating hemiplegia of childhood, rapidonset dystonia-parkinsonism, CAPOS and beyond. Pediatr Neurol 2015;52:56-64.

9. Abela L, Kurian MA. KMT2B-related dystonia. In: Adam MP, Ardinger HH, Pagon RA, et al, eds. GeneReviews. Seattle: University of Washington; 1993.

10. Carecchio M, Mencacci NE, Iodice A, et al. ADCY5-related movement disorders: frequency, disease course and phenotypic variability in a cohort of paediatric patients. Parkinsonism Relat Disord 2017;41:37-43.

11. Chang FCF, Westenberger A, Dale RC, et al. Phenotypic insights into ADCY5associated disease. Mov Disord 2016;31:1033-1040.

12. Dhamija R, Mink JW, Shah BB, Goodkin HP. GNAO1-associated movement disorder. Mov Disord Clin Pract 2016;3:615-617.

13. Feng H, Khalil S, Neubig RR, Sidiropoulos C. A mechanistic review on GNAO1associated movement disorder. Neurobiol Dis 2018;116:131-141.

14. Mink JW, Sanger TD. Movement disorders: an overview. In: Swaiman's Pediatric Neurology: Principles and Practice, 6th ed. Philadelphia: Elsevier; 2017.

15. Mencacci NE, Brüggemann N. KCTD17 is a confirmed new gene for dystonia, but is it responsible for SGCE-negative myoclonus-dystonia? Parkinsonism Relat Disord 2019;61:1-3.

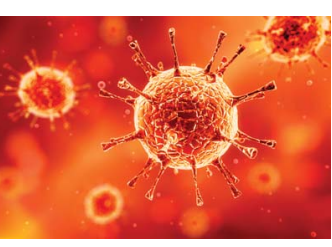

\section{COVID-19 and Neurologic Disease: Call for Papers!}

The editors of Neurology are interested in papers that address the neurological aspects of COVID-19 infection and challenges to the management of patients with chronic neurological conditions who have, or are at risk for, the infection. Relevant papers that pass initial internal review will undergo expedited peer review and online publication. We will consider papers posted in preprint servers.

Submit observational studies and clinical trials as Articles and case series and case reports under the Clinical/Scientific Notes category to https://submit.neurology.org/ today!

\section{Call for Voices: Lived Experiences}

The Editors of the Neurology specialty site Equity, Diversity, \& Inclusion encourage you to submit short first-person accounts (1,000 words or less) of experiences lived within the realm of equity, diversity, and inclusion (EDI) with the goal of informing and enlightening our community on these critical issues. Some topics to consider include, but are not limited to:

- Descriptions of personal experiences that shaped your views of EDI.

- Reflections on the intersection between personal identity and career.

- Discussions at the intersection of EDI and neurology patient care, research, education, advocacy, or policy.

Submit your contributions to journal@neurology.org and include "Voices Submission" in the subject line. 


\section{Neurology}

\section{Child Neurology: Genetically determined dystonias with childhood onset \\ Travis Larsh, Neil Friedman and Hubert Fernandez}

Neurology 2020;94;892-895 Published Online before print February 7, 2020

DOI 10.1212/WNL.0000000000009040

This information is current as of February 7, 2020

Updated Information \& Services

References

Subspecialty Collections

Permissions \& Licensing

Reprints including high resolution figures, can be found at: http://n.neurology.org/content/94/20/892.full

This article cites 12 articles, 1 of which you can access for free at: http://n.neurology.org/content/94/20/892.full\#ref-list-1

This article, along with others on similar topics, appears in the following collection(s):

All Genetics

http://n.neurology.org/cgi/collection/all_genetics

All Movement Disorders

http://n.neurology.org/cgi/collection/all_movement_disorders

Dystonia

http://n.neurology.org/cgi/collection/dystonia

Genetic linkage

http://n.neurology.org/cgi/collection/genetic_linkage

Myoclonus

http://n.neurology.org/cgi/collection/myoclonus

Information about reproducing this article in parts (figures,tables) or in its entirety can be found online at:

http://www.neurology.org/about/about_the_journal\#permissions

Information about ordering reprints can be found online:

http://n.neurology.org/subscribers/advertise

Neurology ${ }^{\circledR}$ is the official journal of the American Academy of Neurology. Published continuously since 1951, it is now a weekly with 48 issues per year. Copyright (O) 2020 American Academy of Neurology. All rights reserved. Print ISSN: 0028-3878. Online ISSN: 1526-632X.

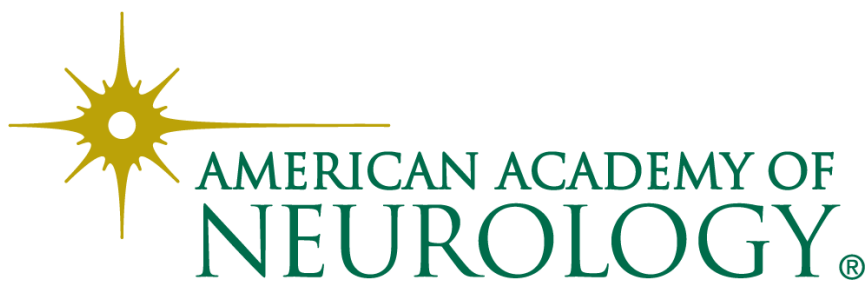

